\title{
Some Regulatory Dilemmas of Artificial Termination of Pregnancy in Slovenian and Comparative Law
}

\author{
VIKTORIJA ŽNIDARŠIČ SKUBIC
}

\begin{abstract}
The article deals with the issue of the artificial termination of pregnancy through the prism of, typically, conflicting relations between the subjects involved and their interests. It specifically addresses the most contentious and morally-ethically as well as legally complicated relationship between the pregnant woman (the future mother) and the embryo or pre-embryo. The article explains the positions of legal theory and jurisprudence in Slovenia and abroad regarding the status of an embryo as a legal person. The authoress moreover touches the question of legal status of the (potential future) father of such an embryo and presents regulations dealing with artificial termination of pregnancy in domestic and comparative law. Through a schematic summary of typical characteristics of such regulations around the world, which greatly differs in details, the author highlights their basic characteristics as well as individual trends in the field.
\end{abstract}

Keywords: • artificial termination of pregnancy $\bullet$ abortion $\bullet$ legal status of embryo $\cdot$ reproductive autonomy $\boldsymbol{~ r i g h t ~ t o ~ t h e ~ a r t i f i c i a l ~}$ termination of pregnancy

CORRESPONDENCE AdDRESS: Viktorija Žnidaršič Skubic, Ph.D., Professor, University of Ljubljana, Faculty of Law, Poljanski nasip 2, 1000 Ljubljana, Slovenia, e-mail: viktorija.znidarsic@pf.uni-lj.si. 
V. Žnidaršič Skubic: Some Regulatory Dilemmas of Artificial Termination of

Pregnancy in Slovenian and Comparative Law

Artificial termination of pregnancy is a specific medical procedure, which in many ways greatly differs from other medical procedures. This procedure involves distinctive conflicts of interest between various subjects: firstly between the mother and the embryo, then between the mother and the father as well as, potentially, between the mother and the doctor (Wicks, 2007: 181). In the article, I will mainly address the following:

a) Does the embryo have a right to life?

b) Does a pregnant woman have a right to artificial termination of pregnancy?

c) Does the child's father have any rights regarding the decision on the artificial termination of pregnancy?

d) Is the doctor bound to act in accordance with the interests of the woman, the embryo or his/her own conscience?

\section{The right of embryo to life}

A fundamental legal dilemma, which arises in the field of artificial termination of pregnancy, is the question whether an embryo has a right to life or whether it has (or should have) been granted the status of a person, and thus a legal personality personality under law (De Cruz, 2002: 145).

The right to life is safeguarded by Article 2 of the European Convention for the Protection of Human Rights and Fundamental Freedoms. ${ }^{1}$ According to the Convention, everyone's right to life should be protected by law. The Convention does not define in more detail whether the term "everyone" also includes embryos or whether it applies only to already born persons which is a crucial issue when dealing with the artificial termination of pregnancy.

The European Court of Human Rights, deciding in 2004 on Vo v France $(53924 / 00),{ }^{2}$ failed to deliver a clear opinion on this long-standing issue despite having had an ideal opportunity to do so. Some believe that the Court missed an ideal opportunity to explicitly rule on the issue, while others accuse the Court of unacceptable deviation from judicial responsibility by sidestepping the issue, as this is one of the main legal, medical, moral and ethical issues of our time (Wicks, 2007: 183 -184). The case is even more important as it does not contain the usual conflict between the rights of the embryo and the rights of its mother.

If we examine the case law of the European Court of Human Rights, we furthermore see that the Court consistently rejected the opportunities to clarify its position on the nature and scope of protection, provided to the embryo by the Convention. This is undoubtedly a reflection of the depth of the existing moral and ethical dilemmas in the field. The question of when human life begins or defining the specific stage 
of human development, when a human being becomes a person and a legal personality, entitled to complete legal protection, including the right to life, seems to be a nut (too) hard to crack. Deciding that a particular moment in the development of a human embryo is to be the defining milestone, be it conception, implantation in the uterus (beginning of pregnancy), the ability to survive outside of the mother's womb or birth, thus always seems to be relatively arbitrary. It can only be a value position by an individual towards an open issue; embryo development from conception onwards is biologically or physiologically a continuing process, where through time (slowly and gradually) a fertilized egg becomes a newborn baby (Glover, 1977: 127).

Many people, mainly due to religious reasons, believe that the defining moment when life begins is fertilization. ${ }^{3}$ Should such a position be adopted, procedures for artificial termination of pregnancy would be inadmissible (regardless of the reasons), as would some means of contraception. ${ }^{4}$ Due to inability to actually protect life from fertilization onwards, as well as due to the unacceptable nature of such action, especially when limiting the rights of the pregnant woman, many do not see absolute protection of an embryo from conception onwards as justified. Similar arguments apply for the next developmental phase: implantation. It seems that a somewhat more generally acceptable stage for the embryo to become entitled to protection is when it can survive outside of the mother's womb (Wicks, 2007: 185). In such a case, we would be hard pressed to say that the mother is justified in artificially terminating the pregnancy by invoking the right to make decisions about her own body or part thereof. The problem with this stage, however, is that the exact moment when the embryo can survive outside of the mother's body cannot be determined absolutely, as it depends on the level of modern technology and the extent to which such technology is available in each individual case. ${ }^{5}$ Some thus believe that this manner of determining the time when an embryo is entitled to legal protection is basically absurd, because it could be argued that maybe last year an embryo at a certain stage was not yet a person, but this year it is, because the intensive care unit for newborn babies has been upgraded in the meantime (Glover, 1977: 125). The final milestone mentioned is childbirth. This is a clear, final and unambiguously manifested event, which also eliminates the difficulties in addressing potential conflicting interests between the embryo and the person carrying it, i.e. the mother. Despite birth seemingly being the most suitable moment to say that an individual's life has begun and thus for extending legal protection to it, the situation is not completely straightforward (Matijević \& Erjavec, 2016: 125). Can society draw such an exacting line? (Wicks, 2007: 186). Regardless of differing views of when human life begins and is entitled to protection, we are nonetheless talking about a human life, which deserves legal and social protection. ${ }^{6}$

I would here like to point to interesting deliberations by Dworkin, who tries to overcome the differences between the eternal dichotomy of opinions in the area of artificial termination of pregnancy, i.e. the pro-life and pro-choice paradigms 
(Dworkin, 1993: 11). Dworkin thus outlines two different types of objections to the artificial termination of pregnancy. He terms the first group of objections as derivative, as they originate from the notion that an embryo has its own rights and interests. The other group of objections is meanwhile made from the sc. independent objections, as the notion of unacceptability of artificial termination of pregnancy in this case does not stem from the rights of the embryo, but rather from denying the value of human life as such. Dworkin believes that, despite (at least at first glance) pro-life rhetoric being based on derivative objections, it is abundantly clear that this only conceals the true nature of their objections. He is of the opinion that a more thorough consideration of arguments against the artificial termination of pregnancy shows that all arguments against it originate from independent objections (Dworkin, 1993: 11). This thus means that the proponents of both camps are in a way connected by the notion that the embryo is a human life which has to be appreciated and that therefore a decision on its survival must be adopted responsibly and with full consideration of the gravity of every specific situation. According to this conclusion, we are no longer discussing the irreconcilable views of two opposing sides regarding the moral and legal status of an embryo, but rather the issue of when a destruction or death of an embryo, which could have been avoided, becomes an unacceptable "frustration of a biological input in life" (Wicks, 2007: 186 - 187).

Based on the presented considerations, we can say that it seems that a majority of people, at least in a certain sense, share the basic idea that human life is sacred and that decisions regarding it must be taken responsibly. This is valid regardless of whether we will ever be able to agree in the future on whether (and if ever) is it justified to artificially terminate it.

\section{Right of mother to artificial termination of pregnancy}

The concept of freedom of choice regarding the birth of children or reproductive autonomy $^{7}$ also has its negative aspect. This means that an integral part of the latter is also the right not to have a child or the right to "non-reproduction", which is widely accepted. Some regulatory frameworks (including Slovenian) take the view that the idea of reproductive autonomy also includes the right to terminate pregnancy or, at least, its slightly ameliorated version, the so called "right to choose". 8

For example, the Supreme Court of Canada found that legislation which forces a woman to carry and bear a child under the threat of a criminal sanction, except in cases where she meets certain assumptions, which are not related to her priorities and desires, constitutes a serious encroachment on her body and in this way represents violation of her right to safety. ${ }^{9}$ Mclean believes that a pregnant woman should be treated as a woman or a human being and not just as an owner of a uterus whose task is to care for the health and well-being of the embryo (Mclean, 2010: $133)$. 
The right of women to artificial termination of pregnancy is also constitutionally protected in the USA. In one of the decisive cases in the field, Roe v Wade, ${ }^{10}$ the US Supreme Court decided that based on the constitutionally guaranteed right to privacy, the right to artificial termination of pregnancy is also protected (Shepherd, 2005: $125-127)$. However the latter is thought of as an absolute right only during the first three months of pregnancy. During the second trimester, artificial termination of pregnancy can be regulated by individual states with the aim to protect the health of the pregnant woman. In the third trimester, individual states can set restrictions for the protection of the embryo. This decision has formed the foundation for numerous conflicts, lasting well into the present, between two American camps: the advocates of pro-life and pro-choice (Wicks, 2007: 190). What is worth mentioning, though, is that the mentioned decision has not angered only pro-life advocates, but also some feminist groups. The latter namely rejected the use of the constitutional right to privacy as a mechanism to safeguard a woman's reproductive autonomy. They said ruling the artificial termination of pregnancy as a personal matter brought at least two harmful consequences to women. Firstly, the decision stresses the fact that sexuality is a private matter in which the state should not interfere. This would mean that potential abuses of women in sexuality would only be sanctioned implicitly. ${ }^{11}$ The feminists moreover feared that such a definition would only oblige the federal governments to allow the artificial termination of pregnancy, but not to (co)finance it. Practice has shown that the second of the two concerns was well founded, as many American authors point out that the right to artificial termination of pregnancy for all is but an empty letter on paper for those without the necessary means (Robertson, 1994: 47). The gap between the constitutional legal admissibility and actual accessibility in practice of the right to artificially terminate pregnancy is considered by many to be the most worrying in the United States (Jackson, 2001: 87), as this right is not financed from the public health purse.

In Europe, however, there exists resistance to defining the artificial termination of pregnancy as a private matter and installing it as such as andividual's right to privacy (Article 8 of ECHR). The European Human Rights Commission dealt with the issue in the case of Bruggemann and Scheuten $v$ Germany (application No. 6959/75). ${ }^{12}$ The case was sparked by a change in the German Penal Code regarding the artificial termination of pregnancy, with the new version stating that it should no longer be unrestricted before the twelfth week of pregnancy. The change followed the German Federal Constitutional Court ruling that the old regulation violated the constitutional obligation to protect the rights and interests of an unborn child. The complainants stated that the new version, which presupposes that an artificial termination of pregnancy is always a punishable offence, though with numerous exemptions, runs contrary to an individual's right to privacy. The Commission rejected the argument, stating that it is impossible to say that pregnancy only refers to an individual's private life. The Commission further stated 
that not every legislation in the area of artificial termination of pregnancy constitutes an interference with the mother's right to privacy. This development means that the decision to artificially terminate pregnancy cannot be solely justified on the basis of Article 8 of ECHR. ${ }^{13}$

Speaking from a legal point of view, the fundamental (conflicting) relationship in the artificial termination of pregnancy is between the mother and the embryo. Nevertheless, it is necessary to shed at least some light on the status on the child's father, at least from a moral and ethical viewpoint. It is a biological fact that the father contributes half of the embryo's genetic material and that his moral responsibility also has clear legal implications in the context of legislating biomedically assisted procreation. The mother and the father hold equal rights regarding an embryo that was conceived outside the body. This was explicitly demonstrated in the case of Evans (application no. 6339/05) ${ }^{14}$ before the ECHR, where the rejection of consent by a man to continue with a bio-medically assisted procreation procedure and implantation of embryos in the body of his ex-girlfriend after breaking up with her, prevented the latter from any possibility of having her own child. ${ }^{15}$ The stated position, i.e. that both parents hold equal rights to the embryo, when it is located outside of the mother's body, is in sharp contrast with the legal assessments in cases when the embryo is located inside the mother's body. In the latter scenario, the father loses all rights to the embryo and such situation lasts until the child is born. The argument for such position is obvious: any intervention by the father, either in terms of preservation or termination of pregnancy, constitutes interference with the mother's body and thus with her right to inviolability of body and (reproductive) autonomy. In such a case, the interests of a mother must overrule those of a father.

There is no doubt in theory that mothers can never be forced to artificially terminate pregnancy. However, some authors have been wondering whether the situation is different in cases where the mother wants to artificially terminate her pregnancy, but the father opposes it (Wicks, 2007: 90). The issue is especially problematic in cases when the father might vouch to take care of the baby by himself and would not demand any emotional or financial contributions from the mother after the baby has been born. Until now only in one case - Trembley v Daigle ${ }^{16}$ - the Canadian High Court issued a temporary ruling that prohibited the mother to carry out an artificial termination of pregnancy. It was later overturned by the Supreme Court, which stressed that there is no mention of father's right in material law on the basis of which such a decision could have been justified. The English law meanwhile explicitly states that in such cases the child's father has no rights in connection with the artificial termination of pregnancy (Wicks, 2007: 198). In the case of Paton $v$ British Pregnancy Advisory Service Trustee ${ }^{17}$ the embryo's father opposed carrying out the artificial termination of pregnancy by stating both the embryo's and his own 
rights. He failed to convince the court, which ruled that, since the law requires neither consultation with nor permission by the child's father, an artificial termination of pregnancy must be carried out as soon as all the conditions (laid down by law) are met (DeCruz, 2002: 157-158). When the case was taken to the European Commission for Human Rights, the latter acknowledged that not taking into account the father's wishes in connection with the artificial termination of pregnancy encroached on his right to private and family life (protected by Article 8 of the ECHR), but ultimately said that the termination was necessary in order to protect the rights of the mother. ${ }^{18}$ This is the prevalent position in the world today and is also accepted in Slovenia.

\section{$5 \quad$ Artificial termination of pregnancy in Slovenia}

The decision to undertake artificial termination of pregnancy in Slovenia is a constitutional right of a pregnant woman who does not want to give birth. This right is provided in the Health Measures in Exercising Freedom of Choice in Childbearing Act (ZZUUP), ${ }^{19}$ even though such a measure is undoubtedly an extremely undesirable means of birth control from both health and social viewpoints. It is an emergency measure, but one which can be very important for the woman, as it is the only way to prevent the birth of a child after conception. ${ }^{20}$

Priority in family planning should in every case be given to prevention, i.e. the use of contemporary and reliable means of contraception. Numerous research has shown that the number of artificial terminations of pregnancy is inversely proportional to the use of modern contraceptives. ${ }^{21}$

Some authors also point to out that it is unclear whether we can truly speak of a freedom of choice in the case of a pregnant woman, who decides to artificially terminate pregnancy. Her decision is usually extremely difficult, as she has to choose between two negative outcomes: a violent termination of pregnancy and a birth of an unwanted child (Zupančič, 1998: 196). It has to be stressed that under certain conditions it is hardly possible to claim that the pregnant woman is entirely aware of all the consequences of her actions in making her choice.

In accordance with the valid Slovenian legislation, termination of pregnancy can be undertaken if requested by the pregnant woman and if the pregnancy has not lasted more than ten weeks. Slovenian law sets no other restrictions, requirements or conditions regarding the artificial termination of pregnancy (Article 17 of ZZUUP).

After ten weeks of pregnancy have passed, the artificial termination of pregnancy is only carried out if its risk to the life and health of the pregnant woman and her future pregnancies is lower than the risk that the pregnant woman or the child is exposed to by the continuation of pregnancy and childbirth. The possible psychological traumas that the future mother is going through are also taken into 
consideration. This late abortion or the artificial termination of pregnancy is decided upon by a level I and level II Commission for the Artificial Termination of Pregnancy. It goes without saying that the decision making procedure in these matters must be very prompt.

After the twentieth week of pregnancy, Slovenian medical practice opposes carrying out the artificial termination of pregnancy, though this limit is not specifically set by law. Exceptions involve cases where the procedure is necessary in order to protect the life and health of the pregnant woman (Zupančič, 1998: 202; Kovaček-Stanić, 2015).

The level I Commission for the Artificial Termination of Pregnancy is composed of a social worker and two doctors. One of the two must be a gynaecologist/obstetrician, who also chairs the commission.

The level II Commission is meanwhile composed of a social worker and three doctors. It is important that all commission members appoint their deputies in order to decide on the cases quickly and promptly. The duration of pregnancy is namely a decisive factor in deciding on the artificial termination of pregnancy, which must still be safe and socially acceptable.

In the event that the pregnant woman is incapable of discernment, the abortion has to be requested by her parents or guardians. In the case of a minor, the hospital usually informs the parents or guardians about her decision, unless she has acquired full legal capacity before coming of age (if she is married or already a mother) (Zupančič, 1998: 157).

According to an explicit legislative provision (Article 23 of the ZZUUP), the request for artificial termination of pregnancy also requires the consent for intervention in accordance with health care regulations. This is the case when artificial termination of pregnancy is requested by a pregnant minor who is capable of discernment, as well as when it is requested by a pregnant woman capable of discernment, but who is deprived of her legal capacity.

The fundamental implementing regulation adopted in the field in order to facilitate the implementation of the ZZUPP in practice is the Instructions for the implementation of the Health Measures in Exercising Freedom of Choice in Childbearing Act. ${ }^{22}$ Article 7(3) of the cited instructions stipulates that a pregnant minor shall be treated with special care and in consideration with her family and social conditions. In doing so, her personal decision is respected, both with regard to the termination of pregnancy and notifying her parents.

After adopting the Patient Rights Act (ZPacP), ${ }^{23}$ the question arose whether a minor capable of discernment under the age of 15 may request an abortion without the 
consent of parents. It should first be stressed that the area of freedom of choice regarding the birth of children is governed by the ZZUUP, since the stated constitutional right from which stem the rights to prevent conception and the artificial termination of pregnancy is regulated by the ZZUUP as a special law. The latter therefore has precedence over the more general, although more recently adopted, ZPacP. ZZUUP is thus a lex specialis and we must comply with its provisions and provisions on the basis of the adopted implementing regulation when addressing the artificial termination of pregnancy, as well as the right to contraception.

According to the above, a minor capable of discernment may independently and without the cooperation or consent of her parents or guardian (or anyone else) request an artificial termination of pregnancy. This can also be done if she has been deprived of her legal capacity, of course, for a reason not relating to her capability for discernment.

In accordance with Slovenian legislation, parents cannot demand that their minor pregnant daughter, who is capable of discernment, should undergo abortion, nor can they prevent her from undertaking artificial termination of pregnancy if she so desires. The right to termination of pregnancy can therefore be asserted by a pregnant woman, provided she is capable of discernment. This means that she must possess the required intellect and will to make her decision, which is confirmed by a doctor on a case-by-case basis through a conversation with the patient during the performance of his explanatory duty (Article 20 of ZPacP).

If the pregnant woman is incapable of discernment, her decision cannot be substituted by the decision of her representative (parent or guardian), as it is a strictly personal choice. The law allows the parents or the guardian to request the termination of pregnancy for their daughter or ward, who is incapable of discernment, however by doing so they do not substitute her will, but rather enforce their obligation to care for the health and life of their daughter or ward (Article 22 of the ZZUPC).

The above regulations were adopted into Slovenian law mainly because artificial termination of pregnancy is one of the most private and personal decisions by an individual. $^{24}$ It is a decision about an important and far-reaching medical intervention that involves one's own body, the most personal human good, which is why the minor herself should make the decision.

A healthcare organization performing the termination of pregnancy usually, though this is not obligatory, informs the parents about the intended or already terminated pregnancy, however, not against the will of the minor. The freedom to decide on childbirth as a constitutionally protected right (Article 55 of the Constitution of the Republic of Slovenia), in principle belongs to an individual when that individual 
can begin to exercise it or has, for example a minor who wishes to artificially terminate pregnancy or use contraception, already begun to exercise it. Parents cannot represent the child in those legal transactions or statements of will, where a child's personal decision is required, which is definitely the case in deciding on such procedures. The child must be free in making such decisions. Freedom of choice would be negated by replacing her will with the will of her parents (guardians) as legal representatives. Representation and freedom of choice are directly opposed to each other. This is why Slovenian law does not require full legal capacity in order to make a strictly personal decision. However, should the child, despite being a minor, possess full legal capacity, the representational function cannot be invoked anyways (Zupančič, 1998: 157).

Similar reasons, as listed for the artificial termination of pregnancy, also apply to the minor's right to temporary contraception, to which a minor, capable of discernment, is entitled to and which she can exercise independently. This means that parents or guardians do not represent her as she exercises this right and that she also does not need their permission or cooperation.

Slovenian regulation regarding abortion is a very old one (it was accepted in late 70's) but it doesn't mean by far that it is also outdated. It consists of a very modern notion that the right to terminate pregnancy is one of the most intimate personal rights of a pregnant women. That is why I believe it should be given the highest possible protection. In Slovenian case, as I already stated, the right of a woman to abortion is protected by the constitution. I'm sure that this kind of regulation that roots in old socialist society and in beliefs that man and women are equal, still expresses the progressive ideas and ideals of today's modern society. I can't think of a better solution to support one of the basic dogma of today's (prevailing) medical ethics - that is the principle of human autonomy when deciding upon the most important questions of his or her life, health and reproduction. I am also sure that this kind of regulation is still supported by the majority of people in Slovenia. It was clearly shown on many occasions in the past, when the conservative government tried to change it or at least make it more difficult. There was always a very strong opposition of a civil society and until now, no government dared to abolish something that is obviously understood as an already acquired right of a woman. I am of the opinion that it would be highly unacceptable to compel women to bear unwanted children. I agree it would represent a form of ethical despotism (Patil, Dode \& Ahirrao, 2014: 548). If all people are to be free, that freedom should also include freedom of women to make these difficult and extremely personal choices by themselves. I would also like to stress that the kind of (liberal) regulation of abortion that is accepted in Slovenian legislation is the most important guarantee for safe and transparent execution of abortion procedures in practice. In that way we protect women before a danger of possible illegal practices that are most common in the jurisdictions with highly conservative regulation on the matter. 
Regulations on artificial termination of pregnancy in comparative law

\subsection{Introduction}

The following paragraphs will list the fundamental regulatory models for artificial termination of pregnancy, which appear in various countries around the world. This will by necessity be a schematic overview, which cannot sum up all the specifics and particularities that characterise individual (national) regulations regarding the termination of pregnancy, but is still beneficial as it can make us aware of the prevalent elements in individual countries or regions.

Four basic (theoretical) models of the artificial termination of pregnancy are known in the world today (Eser \& Koch, 2005: $45-51$ ):
a) prohibition model;
b) pure indication model;
c) combined time limit and indication model;
d) pure time limit model.

\subsection{Prohibition model}

Prohibition model not only prohibits the artificial termination of pregnancy in general, but also grants no exceptions that would allow it or make it go unpunished. The only way for the artificial termination of pregnancy to be carried out unpunished under this system is by handling the with the use of general legal principles or the sc. unwritten exclusions, for example by the use of penal-law definitions that exclude from punishment sc. therapeutic abortions; through reliance on general grounds of justification of a certain deed or through exculpation rules in penal law; or through various other unwritten legal grounds that have the status of quasi-customary law (Berer, 2017).

Such models place the artificial termination of pregnancy in their criminal codes, while the procedural regulations for abortions, should they exist at all, are written in the professional codes of medical associations.

This model is only very rarely used in practice today. Examples of countries where it still exists include Chile, where no exceptions exist, or the United Arab Emirates, where the only exception is due to emergency cases (Hassan, 2011).

\subsection{Pure indication model}

This type of model, similarly to the prohibition model, treats artificial termination of pregnancy as criminal offense, but on the other hand includes explicit exceptions, which render it unpunishable should certain indications exist (Cook, Erdman, 
Dickens, 2016: 375). This particular system does not know any provision of so called blanket exemption from punishment for the artificial termination of pregnancy, unlike, for example, the pure or combined time limit models, which will be presented below.

The pure indication model includes at least five basic variations (Eser \& Koch, 2005: 47 - 48):

- the defined exceptions can either be more or less broad (from highly restrictive and/or minimalist descriptions of the grounds for an exception to the more general - blanket - definitions);

- a graduated and non-graduated indication model (the two versions mainly differ by the first one treating the artificial termination of pregnancy, due to individual indications, as connected to individual key chronological points in an embryo's development, while the second uses the prescribed indications from conception to the birth continuously, i.e. without recognising specific cut-off points in an embryo's development), ${ }^{25}$

- recognition of a sc. chronological aspect (differences between systems here appear mainly in regulating the issue of considering the existence of the early phase of the pregnancy; some countries prohibit abortion from conception onwards, while others enforce the prohibition after implantation has taken place) $;{ }^{26}$

- differences between the systems also appear in procedural rules regarding undertaking the termination of pregnancy (countries set widely differing requirements for exempting the procedure from punishment; for example, that the termination must be undertaken by a physician, in a medical facility, that counselling is present or that the presence of an indication must be formally ascertained by a specific third party etc.);

- some legislations have moreover adopted the regulation that a pregnant woman is in any case exempt from punishment due to carrying out an artificial termination of pregnancy (Berer, 2017).

\subsection{Combined time limit and indication model}

This model fundamentally exempts the artificial termination of pregnancy from punishment if it is undertaken during a specified, initial period of pregnancy. The system of indications for the artificial termination of pregnancy only applies in later stages. ${ }^{27}$

The common tendencies that we can discover in the sc. combined models are:

- the procedural safety during the artificial termination of pregnancy procedure is relatively very significant (it can, for example, require a third-party review of the situation, counselling for the pregnant woman, providing explicit 
explanations and presenting alternatives to the artificial termination of pregnancy, followed by a short waiting period to allow the pregnant woman to reconsider them);

- the time turning point between using the system of indications and the initial time limit when the artificial termination of pregnancy is exempt from punishment is generally the $12^{\text {th }}$ week;

- pregnant women are generally exempt from punishment;

- this model is predominantly used in countries which adopted their legislation in the area of the artificial termination of pregnancy after the reform endeavours in the 1950's (The National Institute for Reproductive Health, 2017: 3; Kovaček-Stanić, 2015).

\subsection{Pure time limit model}

The sc. pure time limit model exempts the artificial termination of pregnancy from punishment within a specific time period, without the need for any indication to be present (UN Department of Economic and Social Affairs, 2016: 6). Such regulations do not specify a subsequent period, during which an indication is required, as was the case with the previous model. This model has been adopted by a relatively few countries, and it includes two different positions (Eser \& Koch, 2005: 50-51):

- in connection with the protection of an unborn child, some countries place an upper time limit for the artificial termination of pregnancy (generally at around 24 weeks);

- some countries, however, place no such time limit regarding the artificial termination of pregnancy; such regulations apparently are not concerned with protecting the embryo, but rather mainly the pregnant woman and her interests or even pursue the interests of general demographic policy. ${ }^{28}$

\section{$7 \quad$ Conclusion}

The schematically presented legislative models that regulate artificial termination of pregnancy in comparative law can, despite neglecting individual details, serve as a suitable foundation to analyse and compare different legislative starting points. We can focus on three basic questions, which must be addressed by practically all regulations that deal with the area of the artificial termination of pregnancy. The first question is, who is the main subject of protection: the embryo or the mother? The second relevant dilemma concerns the role of the pregnant woman in deciding whether or not to terminate the pregnancy. And the third question deals with the level of social acceptability or unacceptability of pregnancy termination.

It stems from the above that no legal regulation exists in the world nowadays that would include complete prohibition against the killing of developing human life or guarantee absolute protection to the life of an unborn being. Such an approach does 
not exist even in the countries with the prohibitive model, where exceptions mainly occur due to therapeutic artificial termination of pregnancy, which is necessary in order to safeguard the pregnant woman's health or life. This in turn means that guaranteeing the rights of the embryo is always relative in today's world. ${ }^{29}$

At the other side of the spectrum, we can find countries that have no upper time limit for carrying out the artificial termination of pregnancy (such as Bahrain and China) (UN Department of Economic and Social Affairs, 2016: 6). Despite that, theoreticians have stated that even those countries, regardless of the appearance of complete autonomy of the pregnant mother, cannot completely eschew regulation in this area, if they want to maintain a professionally adequate level of artificial termination of pregnancy procedures (so as to protect the pregnant woman's life and health). In the end, this means that even in pure time limit models, the decision on the artificial termination of pregnancy cannot be completely subordinated to the will of the pregnant woman (Eser \& Koch, 2005: 52 - 53). Between these two extreme ways of regulating the issues of the artificial termination of pregnancy, we can identify three basic regulatory positions, which are the most widely used in practice today. They are the sc. more restrictive, more permissive and the sc. urgent models of the artificial termination of pregnancy. In the first, the priority for legal protection lies with the embryo. Artificial termination of pregnancy is thus clearly criminalised and regulated by criminal law. Exceptions that exempt artificial termination of pregnancy from punishment are very narrowly formulated. They mainly include medical indications, but generally dismiss the sc. social emergency situations (Troup Buchanan, 2015). Countries with a more restrictive legislation in the area of the artificial termination of pregnancy include: Ireland, ${ }^{30}$ Poland,,${ }^{31}$ many Latin American countries, such as Argentina and Brazil, and the Arab-African region: Egypt, Iraq, United Arab Emirates, Algeria, Jordan etc. (UN Department of Economic and Social Affairs, 2016: 5). Legislation that is based on a more permissive model, bases the exceptions that exempt artificial termination of pregnancy from punishment on specific (legally determined) time limits and the pregnant woman's right to self-determination (Uberoi \& Debruyn, 2016). The pregnant woman's right to self-determination is here at least equal if not even higher in standing to that of the unborn child. For a specific time period, the decision on termination of pregnancy is thus left completely to the pregnant woman. This means that, as a rule, nobody is entitled to examine her decision, neither before nor after the artificial termination of pregnancy. The decision on going forward with the artificial termination of pregnancy can also be her (explicitly defined) right (UN Department of Economic and Social Affairs, 2016: 6). Such legal systems have a lower level of social disapproval for the artificial termination of pregnancy, which consequently means that the provisions regulating these issues are moved from criminal law to other laws, mainly those dealing with health and social security. Such legislative systems regulating the artificial termination of pregnancy can be found in Sweden, ${ }^{32}$ Denmark (Hofverberg, 2015: 9-10), Austria (Zeldin, 2015: 5) and Slovenia. 
The third model could be placed between the mentioned two. The sc. urgency model gives priority in legal protection to the embryo, which is why the artificial termination of pregnancy is an exceptional event, which should be avoided at all costs and is consequently seen as legally disproved. The permission to carry out the artificial termination of pregnancy procedure is only granted in exceptional cases and depends on the balancing of interests of both subjects: the pregnant woman and the embryo (Patil, Dode, Ahirrao, 2014: 548). Such systems, in combination with specific time-frames, provide the pregnant woman with counselling and she must sometimes explain her reasons for the decision to artificially terminate pregnancy to the doctor. However, regardless of the stated (and other possible, mainly procedural) requirements, the final decision for or against the artificial termination of pregnancy remains in the domain of the pregnant woman and her personal judgement. This regulatory system of the artificial termination of pregnancy can be found, for example, in France, Great Britain, Italy, Norway, Belgium, Germany, Switzerland, Luxemburg, the Netherlands, Poland, Canada, Israel and elsewhere (Berer, 2017; Abortion Legislation in Europe, 2015).

\section{Notes}

${ }^{1}$ OJ RS MP, No 7-41/1994 (RS 33/1994).

${ }^{2}$ See http://www.echr.coe.int/Pages/home.aspx?p=home (30 August 2017).

3 Taken historically, it is interesting that this way of thinking has not been present in Christianity forever. Thomas Aquinas thus believed that the embryo is imbued with a soul at the time when we can feel its movements, i.e. between the $14^{\text {th }}$ and $18^{\text {th }}$ week of pregnancy (Furrow et al., 1997: 37).

${ }^{4}$ Some contraception pills not only prevent fertilisation, but also change the endometrium so that it rejects the implantation of a fertilised egg, thus preventing implantation and so pregnancy (Wicks, 2007: 185).

5 For the question of an embryo's ability to become a subject of compensation law, which also deals with the moment when it can survive outside of a mother's body (Wellman, 2005: 74).

${ }^{6}$ It is also necessary to consider the position that we talk about human life before fertilization itself, as both sperm and egg cells are alive separately before fertilization (Furrow et al., 1997: 40).

${ }^{7}$ See Article 55 of the Constitution of the Republic of Slovenia, OJ RS Nos 33I/1991, 42/1997, 66/2000, 24/2003, 69/2004, 69/2004, 69/2004, 68/2006, 47/13, 75/16.

${ }^{8}$ The term has often been criticised by theorists, as it is clear that numerous women who decide to artificially terminate a pregnancy, do not see the latter as a choice but rather as the only possible solution to the situation in which they found themselves (Fox, 1989: 82).

${ }^{9}$ See https://www.ncbi.nlm.nih.gov/pubmed/12041090 (2 September 2017).

${ }^{10}$ See http://caselaw.findlaw.com/us-supreme-court/410/113.html (2 September 2017). See also Furrow et al, 1997: 53 - 57.

${ }^{11}$ Wicks (2007: 191) also believes that this is not the most convincing concern, as the state, should a certain right be constitutionally protected, has to take action if such a right is violated.

${ }^{12}$ See http://hudoc.echr.coe.int/eng\#\{"appno":["6959/75"]\} (2 September 2017). 
13 Judge Fawcett dissented from the decision, stating he believed that the adopted position was not logical. At the moment, when it was decided that Article 8 of ECHR encompasses pregnancy and its artificial termination, any restrictions of such rights should, in his opinion, be defined in Paragraph 2 of Article 8 ECHR. He believed that restrictions to artificial termination of pregnancy in Germany were not based on any of the there listed justified causes, which are necessary in a democratic society (Wicks, 2007: 192.

${ }^{14}$ See http://hudoc.echr.coe.int/eng\#\{ "dmdocnumber":["815166"],"itemid":["001-80046"]\} (2 September 2017).

${ }^{15}$ Some authors criticised this court decision and some judges moreover produced separate dissenting opinions (Žnidaršič Skubic, 2008: 1154 - 1155).

${ }^{16}$ See https://www.ncbi.nlm.nih.gov/pubmed/12041082 (2 September 2017).

17 See https://shop.iclr.co.uk/Subscr/ICLR_LandingPage.aspx?docId=XQB1979-1 September 2017).

${ }^{18}$ In this way thus also grounded in Paragraph 2, Article 2 of ECHR (Wicks, 2007: 198-199).

${ }^{19}$ OJ SRS, No 11/77, 42/86; OJ RS No 70/00.

${ }^{20}$ Post-coital contraception does not cause artificial termination of pregnancy (Cafuta Hlušička, 2013).

${ }^{21}$ See e.g. presentation file, part of the reports of the Republic of Slovenia to contractual United Nations bodies regarding human rights, p. 10, http://vrs3.vlada.si/imis/imisnet.nsf/0/88F0980AA2B4A902C1258190001F6A9C/\$FILE/t2169057.P DF?OpenElement, (3 September 2017). See also http://www.nijz.si/sl/uporaba-varnihmetod-za-preprecevanje-nosecnosti-med-mladostniki-v-porastu-hbsc-2010-0, (3 September 2017).

22 OJ SRS No 15/1977.

${ }^{23}$ OJ SRS No $15 / 2008$.

${ }^{24}$ Such issues are regulated in a similar fashion by countries such as the Netherlands, Sweden, Austria, Denmark and Italy. For more details see Eser \& Koch, 2008: 91-92.

25 The model mentioned last is predominant in Latin American countries and the ArabAfrican region (Eser \& Koch, 2005: 47).

${ }^{26}$ In such a case, the doors are open for post-coital contraception, the sc. "day after pill" or "after the fact" contraception (see Cafuta Hlušička, 2013).

${ }^{27}$ Individual indications can play a specific role in the initial period of pregnancy (Eser \& Koch, 2005: 49 - 50.)

${ }^{28}$ China and its policy of one, now two children, can serve as an example (RTV SLO, 2015).

${ }^{29}$ Compare with the position of some other authors (Berer, 2017; Uberoi, De Bruyn, 2013; Troup Buchanan, 2015).

${ }^{30}$ In accordance with the country's law (Protection of Life During Pregnancy Act 2013), the doctor must confirm that one of the following circumstances is present in order to terminate the pregnancy: - pregnant woman has a serious condition, it is an emergency, where not artificially terminating the pregnancy would threaten the pregnant woman's life, or - the pregnant woman wants to commit suicide (see http://www.irishstatutebook.ie/eli/2013/act/35/enacted/en/pdf, (3 September 2017)).

${ }^{31}$ In accordance with the Polish act, translated as the Act on Family Planning, Protection of the Human Fetus, and Conditions for Pregnancy Termination, a doctor can artificially terminate a pregnancy only if the pregnancy poses a risk to health or life of the pregnant woman, if there exist a danger of serious and irreversible malformation to the foetus or an incurable illness that threatens its life or if the pregnancy has been caused by a criminal act. Artificial termination of pregnancy is only allowed within the first 12 weeks of pregnancy, when the foetus is unable to survive outside of a mother's body (Yatsunska-Poff, 2015: 29). 
V. Žnidaršič Skubic: Some Regulatory Dilemmas of Artificial Termination of Pregnancy in Slovenian and Comparative Law

${ }^{32}$ See https://www.loc.gov/law/help/abortion-legislation/europe.php\#sweden (3 September 2017).

\section{References}

Berer, M. (2017) Abortion Law and Policy Around the World, Health and Human Rights Journal, 19(1), pp. 13-27.

Cafuta Hlušička, E. (2013) Ko je že skoraj prepozno, Naša lekarna, 70, pp. 50-55.

Cook, R. J, Erdman, J. N., Dickens, B. M. (2014) Abortion Law in Transnational Perspective: Cases and Controversies (Philadelphia: University of Pennsylvania Press).

De Cruz, P. (2002) Medical Law (London: Sweet and Maxwell).

Dworkin, R. (1993) Life's Dominion: An Argument about Abortion and Euthanasia (London: Harper Collins).

Eser, A., Koch, H. G. (2005) Abortion and the Law (The Hague: Asser Press).

Fox, M. (1989) A Woman's Right to Choose? A Feminst Critique, in: Harris, J., Holm, S. (ed.) The Future of Human Reproduction: Ethics, Choice and Regulation (Oxford: Claredon Press).

Furrow, B. R., Greaney, T. L., Johnson, S. H., Jost, T. S., Schwartz, R. L. (1997) Bioethics: Health Care Law and Ethics, Third Edition (S.t Paul: West Group).

Glover, J. (1977) Causing Death and Saving Lives (London: Penguin).

Hassan, H. (2011) Abortion and the law in the UAE, available at: https://www.thenational.ae/uae/health/abortion-and-the-law-in-the-uae-1.375815 (October 12, 2017).

Hofverberg, E. (2015) Denmark. In: Abortion Legislation in Europe: pp. 9-10, available at: https://www.loc.gov/law/help/abortion-legislation/abortion-legislation.pdf (3.9.2017).

Jackson, E. (2001) Regulating Reproduction: Law, Technology and Autonomy (Oxford: Hart Publishing).

Kovaček-Stanić, G. (2015) Prekid kasne trudnoće u pravu Srbije i uporednom evropskom pravu, Zbornik radova Pravnog fakulteta u Novom Sadu, 49(2), pp. 483-497.

Matijević, R., Erjavec, K. (2016) Responsibilities of Pregnant Women for on Going Pregnancy - Medical Aspects, Medicine, Law \& Society, 9(2), pp. 121 - 129, doi: 10.18690/24637955.9.2.121-130(2016).

Mclean, S. A. M. (2010) Autonomy, Consent and the Law (London: Routledge - Cavendish).

Patil, A. B., Dode, P., Ahirrao A. (2014) Medical Ethics in Abortion, Indian Journal of Clinical Practice, 25(6), pp. 544 - 548. Available:

Robertson, J. A. (1994) Children of Choice: Freedom and the New Reproductive Technologies (Princeton: Princeton University Press).

RTV SLO (2015) Kitajska po 36 letih opušča politiko enega otroka, available: www.rtvslo.si (September 2, 2017).

Shepherd, D. (2005) Bioethics and the Law (New York: Aspen Publishers).

The National Institute for Reproductive Health (2017) When Self-Abortion is a Crime: Laws That Put Woman at Risk (New York: The National Institute for Reproductive Health).

Troup Buchanan, R. (2015) International Abortion Laws: The Six Nations Where it is Still Illegal to Have an Abortion, available at: http://www.independent.co.uk/life-style/healthand-families/international-abortion-laws-the-six-nations-where-it-is-still-illegal-tohave-an-abortion-10229567.html (October 12, 2017).

Uberoi, D., De Bruyn, M. (2013) Human Rights versus legal control over women's reproductive self-determination, Health and Human Rights Journal, 15(1). 
V. Žnidaršič Skubic: Some Regulatory Dilemmas of Artificial Termination of Pregnancy in Slovenian and Comparative Law

UN Department of Economic and Social Affairs (2016) Abortion Policies and Reproductive Health around the World (Washington DC: United Nations).

Wellman, C. (2005) Medical Law and Moral Rights (Dordrecht: Springer).

Wicks, E. (2007) Human Rights and Healthcare (Oxford: Hart Publishing).

Yatsunska-Poff, O. (2015) Poland. In: Abortion Legislation in Europe: p. 29, available at: https://www.loc.gov/law/help/abortion-legislation/abortion-legislation.pdf (September $3,2017)$.

Zeldin, W. (2015) Austria. In: Abortion Legislation in Europe: p. 5, available at: https://www.loc.gov/law/help/abortion-legislation/abortion-legislation.pdf (September 3, 2017).

Zupančič, K. (1998) Pravna ureditev prekinitve nosečnosti, In: Polajnar-Pavčnik, A. \& Wedam Lukić, D. (ed.) Pravo in medicina (Ljubljana: Cankarjeva založba).

Žnidaršič Skubic, V. (2008) The Issue of Consent in Bio-Medically Assisted Reproduction Procedures (The Case of "Evans V. the United Kingdom), Zbornik Pravnog Fakulteta $u$ Zagrebu, 5, pp. $1141-1158$. 